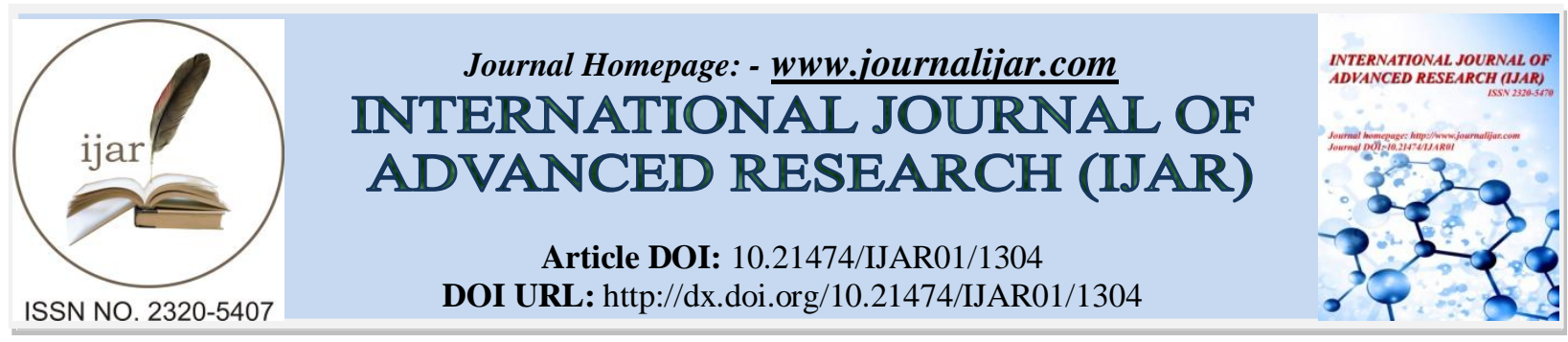

RESEARCH ARTICLE

\title{
AKI IN ICU PATIENTS AND ITS POSSIBLE RELATION TO INTRA-ABDOMINAL HYPERTENSION.
}

\author{
Sabry A. Gohar ${ }^{1}$, Hayam M. Aref ${ }^{1}$, Hanan M. Fouad ${ }^{2}$ and Hussein S. Hussein ${ }^{1}$.
}

1. Internal Medicine Department, Division of Nephrology Ain shams University, Faculty of Medicine.

2. Ministry of Health, Egypt,Cairo.

\section{Manuscript Info}

Manuscript History

Received: 15 June 2016

Final Accepted: 22 July 2016

Published: August 2016

Key words:-

AKI, intra-abdominal hypertension (IAH), ICU

\section{Abstract}

Objective:- Increase in intra-abdominal pressure (IAP) is a clinical condition developed by approximately half of Intensive Care Unit (ICU) patients. This study aimed to investigate the possible relationship between intra-abdominal hypertension and AKI in ICU patients.

Patients and methods:- this study was a cross-sectional observational study, in which 40 patients were included and divided into 2 groups: Group 1: 20 patients having AKI and Group 2: 20 patients with no AKI for whom IAP was measured as a control. Renal function was evaluated according to the Acute Clinical Practice Guidelines for AKI. Intravesical pressure measurement was done as a reflection for intraabdominal pressure on admission to the ICU and 48 hours after.

Results:- The mean IVP on ICU admission was $14.85 \pm 1.28 \mathrm{mmHg}$ and $7.57 \pm 2.39 \mathrm{mmHg}$ in groups 1 and 2 respectively, the difference between the two groups was statistically significant $(\mathrm{p}=0.00)$; whereas the mean intra-vesical pressure after 48 hours from ICU admission was $20.20 \pm 1.73 \mathrm{mmHg}$ and $10.30 \pm 3.25 \mathrm{mmHg}$ in groups 1 and 2 respectively and the difference was also statistically significant ( $p$ value $=0.00$ ). ROC curve analysis has shown that both admission and follow up IVPs had the same diagnostic criteria with the same AUC (0.994); but admission IVP had two advantages; predicting AKI at lower value $(11.0 \mathrm{mmHg}$ versus $15.0 \mathrm{mmHg}$ for IVP-1) and also earlier prediction of AKI.

Conclusion:- IAH is a frequent finding in ICU patients having AKI. Measurement of intra-vesical pressure upon ICU admission can predict the occurrence of AKI.

Copy Right, IJAR, 2016,. All rights reserved.

\section{Introduction:-}

For several decades, increased IAP has been increasingly recognized as both cause and consequence of many adverse events in critically ill patients. Increased IAP within the closed anatomic volume of the abdominal cavity can lead to decreased perfusion and ischemia of intra-abdominal organs. In addition, increased IAP also leads to physiologic changes and organ dysfunction beyond the abdominal cavity because of the close anatomic relationships with contiguous cavities. Depending on the severity of increased IAP and organ function, the conditions are defined as intra-abdominal hypertension (IAH) or Abdominal Compartment Syndrome ACS(1). The presence of two consecutive values of IAP above $12 \mathrm{mmHg}$ characterizes the Intra-Abdominal Hypertension (IAH) that in extreme 
values constitutes the Abdominal Compartment Syndrome (ACS), defined by an IAP >20 mmHg associated to the organic dysfunction(1),(2),(3),(4),(5),(6)Although multi-organ failure is also well recognized in ACS, what is much less appreciated and what some recent data suggest is that kidneys may be particularly at risk with much lower levels of IAP than would be seen in fully established ACS. These findings indicate that AKI resulting, at least in part, from lesser degrees of IAH may be present in a much larger population of critically ill patients than believed previously(7).

The purpose of this study was to assess the possible relationship between intra-abdominal hypertension and acute kidney injury in a sample of our ICU patients.

\section{Patients and methods:-}

This cross-sectional observational study was conducted on 40 consecutive ICU patients in Ain Shams University Hospitals in the period from March 2015 to June 2015. This study was approved by the Ain Shams faculty of medicine Ethical Committee.

The inclusion criteria were patients aged over 18 years. Patients were excluded when they were diagnosed with ESRD on dialysis or contraindications for measurement of IAP found such as bladder or urethral injury. The 40 included patients were divided into 2 groups:

\section{AKI group(group 1):-}

20 patients having AKI and Non-AKIgroup(group 2): 20 patients with no AKI (matched for age and sex) for whom IAP was measured as a control. Renal function was evaluated according to the Acute Clinical Practice Guidelines for AKI.

The following data were collected at the patient's admission: age, sex, anthropometric measures (including weight, height, BMI), pre-existing co-morbidities, history of abdominal trauma, operations, presence of intra-abdominal or retroperitoneal tumor, abdominal burns, primary cause of ICU admission, presence of sepsis [ defined as at least two of the following signs and symptoms (SIRS) that are both present and new to the patient and suspicion of new infection: $\square$ Hyperthermia $>38.3^{\circ} \mathrm{C}$ or Hypothermia $<36^{\circ} \mathrm{C} \square$ Acutely Altered Mental Satus $\square$ Tachycardia $>90 \mathrm{bpm}$ $\square$ Tachypnea $>20$ bpm $\square$ Leukocytosis $>12,000$ or Leukopenia $<4,000$ or $>10 \%$ bands. $\square$ Hyperglycemia $(>120$ $\mathrm{mg} / \mathrm{dl}$ ) in the absence of diabetes].Fluid balance in studied subjects was also recorded and any renal replacement therapy given, presence or absence of mechanical ventilation (defined as the use of invasive positive pressure ventilation through an endotracheal tube or a tracheostomy tube) was also documented. Laboratory investigations included complete blood count(CBC), liver function tests, BUN and Serum creatinine (on admission and after 48 hours, and on discharge), Arterial blood gases(ABGs) on admission and after 48 hours. Intravesical pressure measurement as a reflection for the intra-abdominal pressure was done on admission and after 48 hours.IAP was measured intravesically via a Foley catheter, according to the U-tube manometer technique (8),(9). The sterile saline instillation volume was no more than $25 \mathrm{~mL}$, according to the World Society of the Abdominal Compartment Syndrome consensus(10). IAP was measured in the supine position at the end of expiration after ensuring that abdominal muscle contractions were absent. The symphysis pubis was considered the reference line, and the pressure was expressed in $\mathrm{mmHg}(8),(9),(10)$.

Continuous and parametric variables were expressed as mean \pm standard deviation, continuous and non-parametric variables were expressed as median and inter-quartile range (IQR), and the categorical variables were expressed in absolute number and percentage. The receiver-operating characteristic (ROC) curve was drawn in order to detect the optimal cut-off point as well as the area under the curve and 95\% confidence interval (CI 95\%). The ROC curve provides information on the trade off between sensitivity and specificity for each cut off point of and index. The optimal cut off point for IAP was considered as the highest combined value of sensitivity and specificity: "Youden index". The groups were compared by chi-square for categorical variables, by " $t$ " test for normally distributed variables and Mann-Whitney test for non-normally distributed variables. The p-value of 0.05 was considered statistically significant.

\section{Results:}

The study included sixteen males and twenty four females with mean age $53.75 \pm 5.96$ and $54.40 \pm 12.40$ in groups 1and 2 respectively. The mean Body Mass Index (BMI) was $27.75 \pm 6.16 \mathrm{Kg} / \mathrm{m} 2$ and $22.40 \pm 2.89 \mathrm{Kg} / \mathrm{m} 2 \mathrm{in}$ groups 1 
and 2 respectively. The patients varied in the cause of ICU admission, the most common cause however was hepatic pre-coma ( $\mathrm{n}=24,60 \%)$. Regarding exposure to surgery prior to ICU admission, seven patients from group 1 and four patients from group 2 were exposed to surgery prior to ICU admission and the difference was statistically non significant $\left(\mathrm{X}^{2=1.13}, \mathrm{p}=0.29\right)$.

Ten patients from group 1 and three patients from group 2 suffered from sepsis, with significant difference between both groups $\left(\mathrm{X}^{2=} 5.58, \mathrm{p}=0.02\right)$. The number of patients who received mechanical ventilation was six in group 1 and two in group 2 , the difference being statistically non significant $\left(X^{2=} 2.50, p=0.11\right)$.

Regarding intra-vesical pressure on ICU admission; the mean was $14.85 \pm 1.28 \mathrm{mmHg}$ and $7.57 \pm 2.39 \mathrm{mmHg}$ in groups 1 and 2 respectively, the difference between the two groups was statistically significant $(p=0.00)$; whereas for intra-vesical pressure after 48 hours from ICU admission the mean was $20.20 \pm 1.73 \mathrm{mmHg}$ and $10.30 \pm 3.25 \mathrm{mmHg}$ in groups 1 and 2 respectively and the difference between the two groups was also statistically significant ( $\mathrm{p}$ value $=0.00$ ). Regarding the correlation of IVP1 (intra-vesical pressure after 48hrs from ICU admission) with different numerical variables measured in group1 using Pearson`s test, there was significant positive correlation between IVP1 and each of haemoglobin and serum Creatinine on ICU admission $(\mathrm{Cr} 0)$, serum Creatinine after 48 hours from ICU admission $\left(\mathrm{Cr}_{1}\right)$, serum Creatinine on discharge from ICU $\left(\mathrm{Cr}_{2}\right)$ and Body Mass Index (BMI), while there was significant negative correlation between IVP1 and AST, INR, $\mathrm{PH} 0, \mathrm{PH} 1$ and $\mathrm{HCO}_{3} \mathrm{O}$. ROC curve analysis was done to compare the diagnostic performance of admission IVP and IVP after 48 hours to predict AKI. The best cutoff value for IVP 0 to discriminate between groups- 1 and 2 was at $11.0 \mathrm{mmHg}$, at which specificity $(\mathrm{Sp} \%)=95$; sensitivity $(\mathrm{Sn} \%)=100$; negative predictive value $(\mathrm{P}-\%)=$ 100\%; positive predictive value $(\mathrm{P}+\%)=75.1$ and efficacy $\%=62.5$, Are under curve $(\mathrm{AUC})=0.994$, while the best cut-off for IVP-1 to discriminate between groups- 1 and 2 was at $15.0 \mathrm{mmHg}$, at which $\mathrm{Sp} \%=95 ; \mathrm{Sn} \%=100$; $\mathrm{P}-\%=100 \% ; \mathrm{P}+\%=75.1$ and efficacy $\%=62.5, \mathrm{AUC}=0.994$.

\section{Discussion:-}

Intra-abdominal hypertension has a prevalence of at least $50 \%$ in the critically ill population and has been identified as an independent risk factor for death. Yet, many of the members of the critical care team do not assess for intraabdominal hypertension and are unaware of the consequences of untreated intra-abdominal hypertension. Although the means by which kidney function is impaired in patients with ACS is incompletely elucidated, available evidence suggests that the most important factor involves alterations in renal blood flow. IAH should be considered as a potential cause of acute kidney injury in critically ill patients; its role in other conditions, such as hepatorenal syndrome, remains to be elucidated(1).Numerous conditions such as abdominal surgery, severe pancreatitis, mechanical ventilation, sepsis, ileus, and massive fluid resuscitation are known risk factors for IAH. Sepsis syndrome, the most common cause of admission to a medical ICU, requires massive fluid resuscitation to maintain hemodynamic stability, or mechanical ventilation to treat combined pneumonia or adult respiratory distress syndrome. All these measures are likely to increase IAH and can lead to the development of AKI in critically ill patients(11),(12). Some studies have reported that increased IAP is associated with increased frequency of Intraabdominal pressure as a predictor of acute kidney injury AKI $(1,3,5,6,13-16)$, however, for the best of our knowledge, no Egyptian study reported the predictive value of measurement of intra-vesical pressure to further development of AKI. In the present study, IAP was higher in AKI patients compared to the non-AKI patients. This goes with data from previous studies that a random critically ill patient with renal failure has a higher value of IAP than a random patient without renal failure in $85 \%$ of cases (3),(17). We found that in our AKI sample, there was a significant positive correlation between IAP and BMI. Sugerman et al. (18) reported a positive correlation between bladder pressures and the sagittal abdominal diameter (SAD) and found that surgical patients with a mean BMI of $52 \pm 1 \mathrm{~kg} / \mathrm{m} 2$ had an IAP of $13.2 \pm 0.5 \mathrm{mmHg}$ versus surgical patients with a BMI of $24 \pm 2 \mathrm{~kg} / \mathrm{m} 2$, where the IAP was significantly lower at $5.1 \pm 1.2 \mathrm{mmHg}$. Similar results of elevated IAP have been reported by Sanchez(19) where IAP was higher in patients with a high BMI. The mean IAP for patients with a BMI of $25.0-29.9 \mathrm{~kg} / \mathrm{m} 2$ and $30-39.9 \mathrm{~kg} / \mathrm{m} 2$ was $6.3 \pm 2.9$ and $8.9 \pm 3.5 \mathrm{mmHg}$, respectively. Our results have shown that there was nonsignificant correlation between mechanical ventilation and intra-vesical pressure in the AKI group. In literature, there is some controversy with regard to the effect of mechanical ventilation and the use of PEEP on IAP. Sussman (20)was the first to look at the effects of PEEP on IAP and showed in their experiment that increasing PEEP to 15 $\mathrm{cm}$ of $\mathrm{H} 2 \mathrm{O}$ did not affect the IAP. This was confirmed by animal data (21),(22). In our sample population, IVP was found to be positively correlated with the amount of fluid balance given. Although intravascular fluid replacement was proposed to prevent the deleterious effects of IAH on renal function (23), this approach does not seem to 
prevent ARF and may favour IAH occurrence. Recently, several authors have found a strong correlation between positive fluid balance and increased IAP in surgical and trauma patients(24),(25). Furthermore, in surgical critically ill patients, net fluid balance has been recognized as the only causative factor of $\operatorname{ACS}(26)$ On the other side, a negative fluid balance, obtained by means of aggressive ultrafiltration, has been recently proposed among the conservative strategies to decrease IAP in patients with IAH(27). We also found that IVP correlated positively with the presence of preceding surgery prior to ICU admission, this goes with several studies. An epidemiological multicenter study evaluated 14 ICUs in six different countries including Brazil and the occurrence of IAH was 27\% (4). However, that study evaluated not only PO of abdominal surgeries and did not evaluate specifically the renal consequences of IAH. Many other studies as well reported the incidence of IAH in the PO period of abdominal surgeries, from 4 to $41 \%$ (28),(29),(30),(31). Moreover, another study reported an incidence of 23\% of primary IAH (associated with injury or disease in the pelvic abdominal region) in intensive care patients (32). In our study ROC analysis has shown that both admission and follow up IVPs had the same diagnostic criteria with the same AUC (0.994); but IVP 0 had two advantages; that is predicting AKI at lower value (cut-off value 11.0 $\mathrm{mmHg}$ Vs $15.0 \mathrm{mmHg}$ for IVP-1) and also earlier prediction of AKI on admission Vs 48hrs. after admission for IVP-1), At this best cut-off value of $11 \mathrm{mmHg}$, sp.is $95 \%, \mathrm{Sn} .100 \%$,p-100\%, and p+95.2\%, and eff. is $97.5 \%$. So , we can speculate that single finding of a high intra-vesical pressure on admission to the ICU (> $11 \mathrm{mmHg}$ ) can strongly predict the development of AKI, this is in accordance with previous studies which have found that in liver recipients, renal impairment has been found to be independently correlated with IAH and the most sensitive and specific IAP value for ARF was found to be $25 \mathrm{mmHg}(17)$, however, in a mainly medical population of critically ill patients values of IAP $>12 \mathrm{mmHg}$ on admission were associated with a greater degree of renal dysfunction, as compared with controls(4). Some limitations of this study should be recognized. The reduced number of patients included in the study could compromise the statistical power and may limit the generalization of the findings. Our patients were retrieved from three ICUs (two medical ICUs and one surgical ICU) in one center (Ain Shams University hospitals) only. The former might have contributed to the relatively large number of hepatic patients recruited in this study and consequently the correlations of IAP and each of AST and INR that were not retrieved in any of the previous studies and need to be confirmed in further studies. The number of patients studied is very small and together with an overwhelmingly high number of hepatic patients in the study limits the general applicability of the study findings unless large, multi-center prospective studies are done to confirm and validate such results.

Also, as IAP was measured only for the first 2 days, the effect of a changing pattern of IAP during hospitalization could not be determined.

Tables and figures:-

Table 1:- Baseline demographic and laboratory data between groups 1 and 2.

\begin{tabular}{|c|c|c|c|c|c|}
\hline \multirow{2}{*}{\multicolumn{2}{|c|}{ Variable }} & \multicolumn{2}{|l|}{ Group } & \multirow[t]{2}{*}{$\mathrm{t}$} & \multirow[t]{2}{*}{$\mathrm{P}$} \\
\hline & & 1 & 2 & & \\
\hline \multicolumn{2}{|l|}{ Age } & $53.75 \pm 5.96$ & $54.40 \pm 12.40$ & 0.21 & $0.83(\mathrm{NS})$ \\
\hline \multirow[t]{2}{*}{ Sex } & Male & 8 & 8 & $\mathrm{X}^{2}$ & \multirow[t]{2}{*}{$1.00(\mathrm{NS})$} \\
\hline & Female & 12 & 12 & 0.00 & \\
\hline \multirow{2}{*}{\multicolumn{2}{|c|}{ BMI }} & \multirow[t]{2}{*}{$27.75 \pm 6.16$} & \multirow[t]{2}{*}{$22.40 \pm 2.89$} & $\mathrm{t}$ & \multirow[t]{2}{*}{$0.00(\mathrm{~S})$} \\
\hline & & & & 3.52 & \\
\hline \multicolumn{2}{|l|}{ Hemoglobin } & $9.85 \pm 1.79$ & $10.50 \pm 1.58$ & 1.22 & $0.23(\mathrm{NS})$ \\
\hline \multicolumn{2}{|l|}{ WBC } & $17.06 \pm 11.39$ & $8.85 \pm 5.11$ & 2.94 & $0.01(\mathrm{~S})$ \\
\hline \multicolumn{2}{|l|}{ Platelets } & $196.00 \pm 147.07$ & $136.00 \pm 106.26$ & 1.48 & 0.15 (NS) \\
\hline \multicolumn{2}{|l|}{ ALT } & $27.60 \pm 9.62$ & $43.35 \pm 28.06$ & 2.38 & $0.02(\mathrm{~S})$ \\
\hline \multicolumn{2}{|l|}{ AST } & $34.60 \pm 18.97$ & $45.50 \pm 26.23$ & 1.51 & $0.14(\mathrm{NS})$ \\
\hline \multicolumn{2}{|l|}{ Alb } & $3.05 \pm 0.79$ & $2.61 \pm 0.71$ & 1.86 & 0.07 (NS) \\
\hline \multicolumn{2}{|l|}{ INR } & $2.26 \pm 0.87$ & $1.40 \pm 0.33$ & 4.14 & $0.00(\mathrm{~S})$ \\
\hline \multicolumn{2}{|l|}{$\mathrm{Cr} 0$} & $2.08 \pm 0.86$ & $0.87 \pm 0.25$ & 6.04 & $0.00(\mathrm{~S})$ \\
\hline \multicolumn{2}{|l|}{$\mathrm{Cr} 1$} & $2.58 \pm 1.04$ & $0.87 \pm 0.25$ & 7.17 & $0.00(\mathrm{~S})$ \\
\hline \multicolumn{2}{|l|}{$\mathrm{Cr} 2$} & $2.21 \pm 1.09$ & $0.87 \pm 0.25$ & 5.33 & $0.00(\mathrm{~S})$ \\
\hline \multicolumn{2}{|l|}{ BUN } & $52.70 \pm 21.44$ & $23.20 \pm 10.57$ & 5.52 & $0.00(\mathrm{~S})$ \\
\hline
\end{tabular}

$0=$ value on ICU admission 
$1=$ value after 48 hrs. from ICU admission

$2=$ value on discharge from ICU

Table 2:- Admission and follow up Intra- vesical pressure in both studied groups

\begin{tabular}{|l|l|l|l|l|}
\hline \multirow{3}{*}{ Variable } & Group & & \multirow{2}{*}{ T } \\
\cline { 2 - 3 } & AKI & Non AKI & 12.03 & P \\
\hline IVP0 & $14.85 \pm 1.28$ & $7.57 \pm 2.39$ & 12.00 \\
\hline IVP1 & $20.20 \pm 1.73$ & $10.30 \pm 3.25$ & 12.03 & 0.00 \\
\hline
\end{tabular}

IVP0 $=$ intra-vesical pressure on ICU admission

IVP1 = intra-vesical pressure after $48 \mathrm{hrs}$. from ICU admission

Table 3:- "Correlation of IVP with the different studied numerical variables in AKI group using Pearson`s test"

\begin{tabular}{|c|l|l|}
\hline Variable & T & $\mathrm{P}$ \\
\hline HB & 0.55 & $0.01 * *$ \\
\hline WBC & 0.11 & 0.65 \\
\hline Plt & 0.21 & 0.37 \\
\hline ALT & -0.17 & 0.49 \\
\hline AST & -0.57 & $0.01^{*}$ \\
\hline Alb. & 0.09 & 0.71 \\
\hline INR & -0.53 & $0.02^{*}$ \\
\hline Cr0 & 0.69 & $0.00 * *$ \\
\hline Cr1 & 0.53 & $0.02 * *$ \\
\hline Cr2 & 0.77 & $0.00 * *$ \\
\hline BUN & -0.09 & 0.68 \\
\hline BMI & 0.61 & $0.00^{*} 8$ \\
\hline PH0 & -0.64 & $0.00 *$ \\
\hline PH1 & -0.48 & $0.03 *$ \\
\hline Volume of fluids given in 24 hrs. & 0.88 & $0.00^{* *}$ \\
\hline
\end{tabular}

$0=$ value on ICU admission

$1=$ value after $48 \mathrm{hrs}$. from ICU admission

$2=$ value on discharge from ICU

Table 4:- " Correlation of IVP with the different studied nominal variables in AKI group using Spearman`s test".

\begin{tabular}{|l|l|l|}
\hline Variable & rho & P \\
\hline Surgery & 0.52 & $0.02^{*}$ \\
\hline Sepsis & 0.47 & $0.04^{*}$ \\
\hline Mechanical Ventilation & 0.22 & 0.35 \\
\hline Ascites & 0.49 & $0.03^{*}$ \\
\hline
\end{tabular}

Figure 1:- "Correlation between IVP1 and amount of fluid therapy given per 24 hours among patients in group1" 


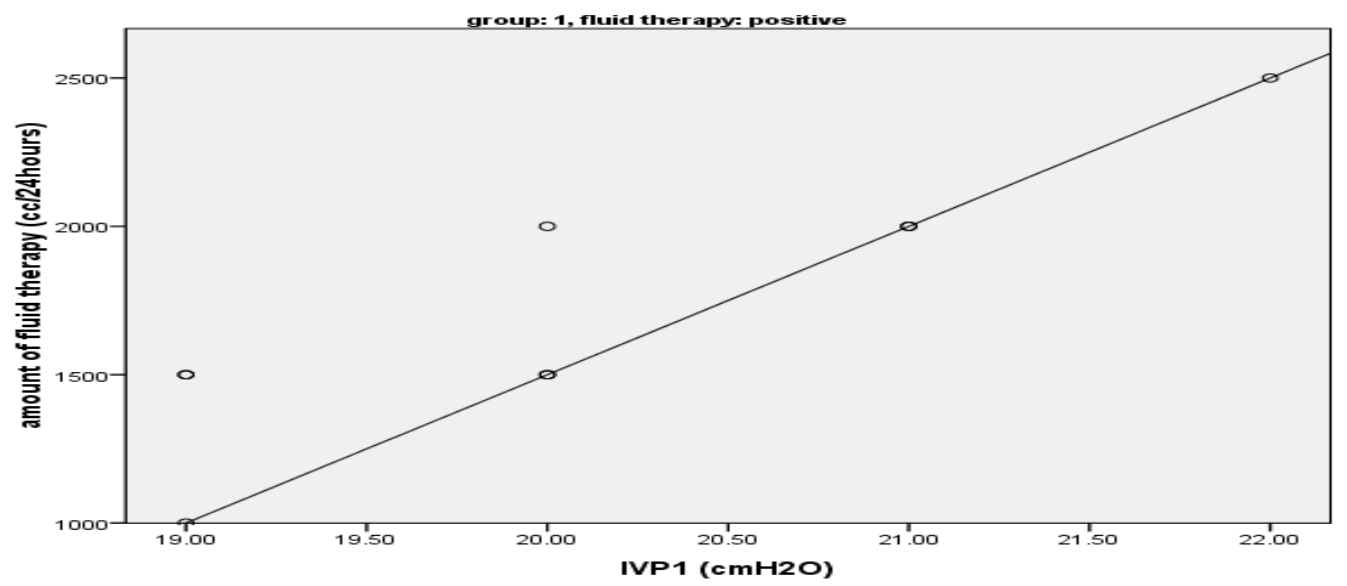

Figure 2: "ROC curve analysis showing the diagnostic performance of admission IVP "
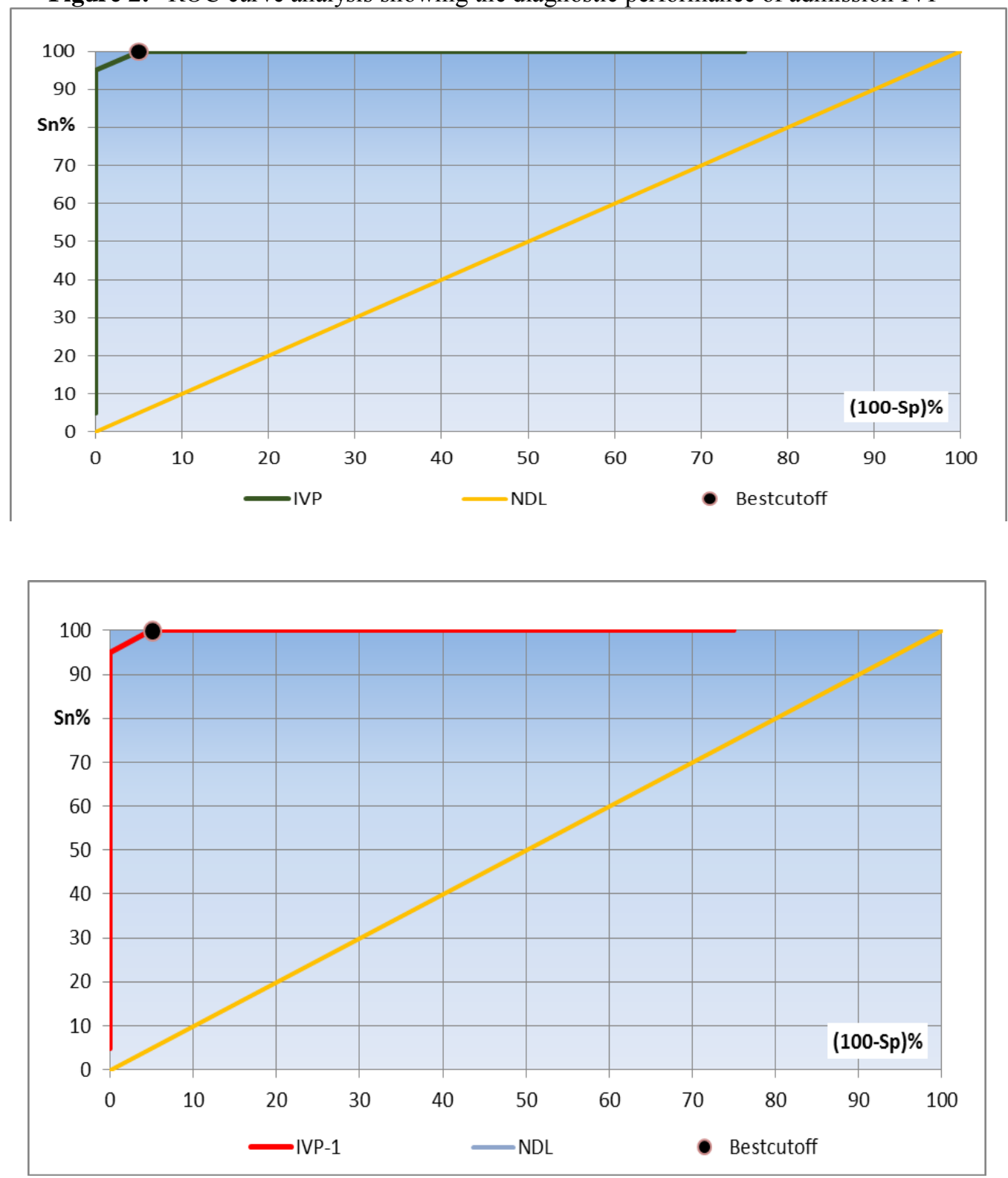
Figur3:- " ROC curve analysis showing the diagnostic performance of follow up IVP “

\section{References:-}

1. De Waele JJ, De Laet I, Kirkpatrick AW, Hoste E. Intra-abdominal Hypertension and Abdominal Compartment Syndrome. Am J Kidney Dis. Jan;57(1):159-69.

2. De Keulenaer BL, De Waele JJ, Powell B, Malbrain ML. What is normal intra-abdominal pressure and how is it affected by positioning, body mass and positive end-expiratory pressure? Intensive Care Med. 2009 Jun;35(6):969-76.

3. Dalfino L, Tullo L, Donadio I, Malcangi V, Brienza N. Intra-abdominal hypertension and acute renal failure in critically ill patients. Intensive Care Med. 2008 Apr;34(4):707-13.

4. Malbrain ML, Chiumello D, Pelosi P, Bihari D, Innes R, Ranieri VM, et al. Incidence and prognosis of intraabdominal hypertension in a mixed population of critically ill patients: a multiple-center epidemiological study. Crit Care Med. 2005 Feb;33(2):315-22.

5. IVidal MG, Ruiz Weisser J, Gonzalez F, Toro MA, Loudet C, Balasini C, et al. Incidence and clinical effects of intra-abdominal hypertension in critically ill patients. Crit Care Med. 2008 Jun;36(6):1823-31.

6. De Waele JJ, Leppaniemi AK. Intra-abdominal hypertension in acute pancreatitis. World J Surg. 2009 Jun;33(6):1128-33.

7. Mullens W, Abrahams Z, Skouri HN, Francis GS, Taylor DO, Starling RC, et al. Elevated intra-abdominal pressure in acute decompensated heart failure: a potential contributor to worsening renal function? $\mathrm{J}$ Am Coll Cardiol. 2008 Jan 22;51(3):300-6.

8. Lee RK. Intra-abdominal hypertension and abdominal compartment syndrome: a comprehensive overview. Crit Care Nurse. Feb;32(1):19-31.

9. Malbrain ML. Different techniques to measure intra-abdominal pressure (IAP): time for a critical re-appraisal. Intensive Care Med. 2004 Mar;30(3):357-71.

10. Kirkpatrick AW, Roberts DJ, De Waele J, Jaeschke R, Malbrain ML, De Keulenaer B, et al. Intra-abdominal hypertension and the abdominal compartment syndrome: updated consensus definitions and clinical practice guidelines from the World Society of the Abdominal Compartment Syndrome. Intensive Care Med. Jul;39(7):1190-206.

11. Santa-Teresa P, Munoz J, Montero I, Zurita M, Tomey M, Alvarez-Sala L, et al. Incidence and prognosis of intra-abdominal hypertension in critically ill medical patients: a prospective epidemiological study. Ann Intensive Care. Jul 5;2 Suppl 1:S3.

12. De Laet IE, Ravyts M, Vidts W, Valk J, De Waele JJ, Malbrain ML. Current insights in intra-abdominal hypertension and abdominal compartment syndrome: open the abdomen and keep it open! Langenbecks Arch Surg. 2008 Nov;393(6):833-47.

13. Cheatham ML, Malbrain ML, Kirkpatrick A, Sugrue M, Parr M, De Waele J, et al. Results from the International Conference of Experts on Intra-abdominal Hypertension and Abdominal Compartment Syndrome. II. Recommendations. Intensive Care Med. 2007 Jun;33(6):951-62.

14. De Waele JJ, Cheatham ML, Malbrain ML, Kirkpatrick AW, Sugrue M, Balogh Z, et al. Recommendations for research from the International Conference of Experts on Intra-abdominal Hypertension and Abdominal Compartment Syndrome. Acta Clin Belg. 2009 May-Jun;64(3):203-9.

15. Malbrain ML, Cheatham ML, Kirkpatrick A, Sugrue M, Parr M, De Waele J, et al. Results from the International Conference of Experts on Intra-abdominal Hypertension and Abdominal Compartment Syndrome. I. Definitions. Intensive Care Med. 2006 Nov;32(11):1722-32.

16. Biancofiore G, Bindi ML, Romanelli AM, Bisa M, Boldrini A, Consani G, et al. Postoperative intra-abdominal pressure and renal function after liver transplantation. Arch Surg. 2003 Jul;138(7):703-6.

17. Zweig MH, Campbell G. Receiver-operating characteristic (ROC) plots: a fundamental evaluation tool in clinical medicine. Clin Chem. 1993 Apr;39(4):561-77.

18. Sugerman H, Windsor A, Bessos M, Wolfe L. Intra-abdominal pressure, sagittal abdominal diameter and obesity comorbidity. J Intern Med. 1997 Jan;241(1):71-9.

19. Sanchez NC, Tenofsky PL, Dort JM, Shen LY, Helmer SD, Smith RS. What is normal intra-abdominal pressure? Am Surg. 2001 Mar;67(3):243-8.

20. Sussman AM, Boyd CR, Williams JS, DiBenedetto RJ. Effect of positive end-expiratory pressure on intraabdominal pressure. South Med J. 1991 Jun;84(6):697-700. 
21. Hazebroek EJ, Haitsma JJ, Lachmann B, Steyerberg EW, de Bruin RW, Bouvy ND, et al. Impact of carbon dioxide and helium insufflation on cardiorespiratory function during prolonged pneumoperitoneum in an experimental rat model. Surg Endosc. $2002 \mathrm{Jul} ; 16(7): 1073-8$.

22. Kotzampassi K, Paramythiotis D, Eleftheriadis E. Deterioration of visceral perfusion caused by intra-abdominal hypertension in pigs ventilated with positive end-expiratory pressure. Surg Today. 2000;30(11):987-92.

23. Meldrum DR, Moore FA, Moore EE, Franciose RJ, Sauaia A, Burch JM. Prospective characterization and selective management of the abdominal compartment syndrome. Am J Surg. 1997 Dec;174(6):667-72; discussion 72-3.

24. Biancofiore G, Bindi ML, Romanelli AM, Boldrini A, Consani G, Bisa M, et al. Intra-abdominal pressure monitoring in liver transplant recipients: a prospective study. Intensive Care Med. 2003 Jan;29(1):30-6.

25. Balogh Z, McKinley BA, Cocanour CS, Kozar RA, Valdivia A, Sailors RM, et al. Supranormal trauma resuscitation causes more cases of abdominal compartment syndrome. Arch Surg. 2003 Jun;138(6):637-42; discussion 42-3.

26. McNelis J, Marini CP, Jurkiewicz A, Fields S, Caplin D, Stein D, et al. Predictive factors associated with the development of abdominal compartment syndrome in the surgical intensive care unit. Arch Surg. 2002 Feb;137(2):133-6.

27. Malbrain ML, Deeren D, De Potter TJ. Intra-abdominal hypertension in the critically ill: it is time to pay attention. Curr Opin Crit Care. 2005 Apr;11(2):156-71.

28. Sugrue M, Buhkari Y. Intra-abdominal pressure and abdominal compartment syndrome in acute general surgery. World J Surg. 2009 Jun;33(6):1123-7.

29. Mayberry JC, Welker KJ, Goldman RK, Mullins RJ. Mechanism of acute ascites formation after trauma resuscitation. Arch Surg. 2003 Jul;138(7):773-6.

30. Schachtrupp A, Jansen M, Bertram P, Kuhlen R, Schumpelick V. [Abdominal compartment syndrome: significance, diagnosis and treatment]. Anaesthesist. 2006 Jun;55(6):660-7.

31. Cheatham ML, White MW, Sagraves SG, Johnson JL, Block EF. Abdominal perfusion pressure: a superior parameter in the assessment of intra-abdominal hypertension. J Trauma. 2000 Oct;49(4):621-6; discussion 6-7.

32. Reintam A, Parm P, Kitus R, Kern H, Starkopf J. Primary and secondary intra-abdominal hypertension-different impact on ICU outcome. Intensive Care Med. 2008 Sep;34(9):1624-31. 